\title{
commentary Cognitive-friendly hospitals: a leap from Flat Earthers to Galileo COMMENTARY ON... MANAGING DELIRIUM IN EVERYDAY PRACTICE ${ }^{\dagger}$
}

\author{
David Jolley
}

David Jolley is an honorary reader in old age psychiatry at the University of Manchester. He was formerly Professor of Old Age Psychiatry at the University of Wolverhampton. Correspondence Professor David Jolley, Personal Social Services Research Unit, University of Manchester, Dover Street, Manchester M13 9PL, UK. Email: David.jolley@manchester.ac.uk

${ }^{\dagger}$ See pp. 380-389, this issue.

\begin{abstract}
SUMMARY
General hospitals and hospices see mostly older people, many of whom have dementia and multiple pathologies: delirium is common, costly and damaging. Informed and kindly care can reduce the incidence of delirium and hasten its resolution. O'Connell et al demand ownership of this phenomenon by the whole hospital. This will require a turnabout of philosophy, management and training for all professions.
\end{abstract}

\section{DECLARATION OF INTEREST}

None.

It is a wonderful thing that mothers and babies can face childbirth with every confidence that they will survive. More wonderful still that they go on to expect a healthy, long life before dying in their 80s or beyond (King's Fund 2014). The wealth of our and other nations has purchased better housing, sanitation and nutrition; education and science have given us understanding and the ability to avoid, ameliorate and treat many hazards to health and independence.

Some grumble that even this is not enough and seem to feel that the design should be improved to allow an even longer life. Our healthcare system might be improved upon, but for most of us our extended years will be spent freely in the world of home, work and leisure with access to medical advice if and when we need it. The worlds of hospital and hospice are small, visited infrequently, but valued as safe havens of care and expertise to be called on when all else fails.

\section{The challenge}

O'Connell et al (2014, this issue) join with others in urging hospitals (and maybe hospices) to take heed of the needs of the people who come to them in this 21st century: old people, many of whom will have dementia or be compromised by a period of delirium consequent on reduced cognitive reserve and the stress of physical illness and/or substances prescribed to treat it (George 1997; Tapley 2012).

While others have urged hospitals to be friendly to old people (e.g. the Senior Friendly Hospitals developed by the Regional Geriatric Program of Toronto, Canada: http://seniorfriendlyhospitals.ca) or people with dementia (e.g. the Dementia Action Alliance, in partnership with the NHS Institute for Innovation and Improvement: Dementia Action Alliance 2014), O'Connell and his colleagues point to the particular importance of delirium. This is a seismic step forwards: they suggest that 'delirium has unrivalled penetration across healthcare services', but it is in the places where the most severely ill are cared for and treated that delirium is concentrated and dominates the experience of patients, families and professionals. These places are our general hospital wards and hospices. Delirium is the demon of acute healthcare and palliative care (George 1997; Tapley 2012).

\section{'As is'}

The conveyor-belt 'progressive patient care' model, which sees efficiency in moving individuals from a frantic assessment ward to a specialist unidisciplinary ward, is rarely sympathetic to the whole patient. Thinking is dominated by identification and treatment of a codifiable current physical illness episode. Continuity of care and therapeutic relations across a series of admissions happens only by chance. The contributions of multiple pathologies may not be acknowledged. Influences and consequences which cross modalities between the physical, mental, social and spiritual are not easy to accommodate and may be met with irritation and rejection: 'This patient does not require our specialist skills or resources', 'Her behaviour is upsetting other patients and their relatives have complained that she should be somewhere else', 'Medically fit for discharge', 'Bed-blocker'.

This is a model which might have been fit for previous generations. It is grounded in a view of illness arising from single pathology within an organism (human being) where there are no 
complications. It might be the world of controlled clinical trials where such complications constitute exclusion criteria. In reality, the limitations of this approach are evident. O'Connell and others are seeking to bring the work of hospitals and hospices into line with the characteristics and needs of present-day patients: we are old, have multiple pathologies and vulnerabilities, social and spiritual concerns. Forty per cent of people over 70 years old with unplanned admissions have dementia and $20 \%$ or more will have or will develop short-term cognitive decompensation - delirium.

\section{A better way}

Sensitive, positive attention to these phenomena will see them resolved and improve my prospects for health and well-being in the weeks, months and maybe years which remain of my life. Unfeeling determination to be blind to these other dimensions brings pain and distress to all parties and makes the possibilities of secondary and tertiary complications and impairments all but inevitable: persistent confusion, progress of dementia, longterm prescription of tranquillisers, loss of abilities and independence, admission to care, financial exploitation, death in distress (Tapley 2013).

To counter these hazards requires unclouded appreciation of the realities of our time: the shift in thinking is equivalent to Galileo's illumination of the elegant complexity of the universe from the darkness and ignorance of belief in a flat earth.

The beauty of O'Connell et al's contribution is to take this message for adoption by the whole hospital team: from the board, to chief executive, through finance officers, managers, clinicians of all professions, unqualified staff, administrators and patient and carer representatives. Ownership of these truths across all aspects of hospital life is essential to their success. It will require too, the understanding and commitment of commissioning groups.

\section{Obstacles that remain}

The current workforce is bizarrely ill-equipped: nursing requires students to decide between training in 'adult' medicine or 'mental', yet patients very often have both physical and mental problems, exquisitely demonstrated in delirium. The educational challenges are great, but could be corrected for the present generation of professionals by the application of will and suitable additional education, and deficits avoided for future trainees by appropriate modification of programmes.

The likelihood of delirium can be predicted, preventive measures can be taken and are effective, as are informed approaches to the management and aftercare of people who actually become delirious.
The savings in terms of reduced distress, better use of resources and financial benefits are demonstrable and staggering.

The importance of the mental health of people during their time in hospital and hospice has been appreciated for many years, but only recently has this knowledge been turned into meaningful changes in services on a scale that can have a worthwhile impact. Else Guthrie and others have demonstrated this in patients of all ages (Guthrie 2012) and George Tadros and others have made real progress with their RAID (rapid assessment, interface and discharge) model of liaison (Tadros 2013). In other situations general hospitals themselves have begun to reorganise to the needs of people with cognitive losses (Leung 2010). How strange then that mental health remains segregated into mental health trusts rather than included within the mainstream of specialist hospital and community services.

There is time for a change.

There is easy talk of person-centred care and integration of services, but these compete with the dehumanising concepts of 'clusters' and 'pathways', which are mechanistic rather than biological (Goodwin 2012). 'Friendly' is what we want our hospitals to be when we enter them.

Adopting informed, individualised kindness or friendliness as a mode of operation will ensure a good fit for individuals and organisations (Ballatt 2011).

\section{References}

Ballatt J, Campling P (2011) Intelligent Kindness. RCPsych Publications.

Dementia Action Alliance (2014) The Right Care: Creating Dementia Friendly Hospitals. NHS Institute for Innovation and Improvement (http:// www.dementiaaction.org.uk/therightcare). Accessed 3 Sep 2014.

George J, Bleasdale S, Singleton S (1997) Causes and prognosis of delirium in elderly patients admitted to a district general hospital. Age and Ageing, 26: 423-7.

Goodwin N, Smith J, Davies A, et al (2012) A Report to the Department of Health and the NHS Forum. Integrated Care for Patients and Populations: Improving Outcomes by Working Together. King's Fund \& Nuffield Trust.

Guthrie E, Rao S, Temple M (2012) Seminars in Liaison Psychiatry. RCPsych Publications.

King's Fund (2014) Life Expectancy. The King's Fund (http://www. kingsfund.org.uk/time-to-think-differently/trends/demography/lifeexpectancy). Accessed 3 Sep 2014

Leung D, Todd J (2010) Dementia care in the acute general hospital. Clinical Medicine, 10: 220-2.

O'Connell H, Kennelly SP, Cullen W, et al (2014) Managing delirium in everyday practice: towards cognitive-friendly hospitals. Advances in Psychiatric Treatment, 20: 380-9.

Tadros G, Salama RA, Kingston P, et al (2013) Impact of an integrated rapid response psychiatric liaison team on quality improvement and cost savings: the Birmingham RAID model. Psychiatric Bulletin, 37: 4-10.

Tapley M, Talbot C, Jolley D (2012) The importance of awareness of cognitive impairment in palliative care patients. European Journal of Palliative Care, 19: 58-61.

Tapley M, Piling L, Jolley D, et al (2013) Hospice transfer for patients at the end of life. Nursing Standard, 28 (8): 42-8. 